\title{
Smart Contract Relations in e-Commerce: Legal Implications of Exchanges Conducted on the Blockchain
}

\author{
Philippa Ryan
}

\author{
"A contract is not sufficient unto itself, but is possible") \\ only thanks to a regulation of the contract which is \\ originally social.
}

Émile Durkheim (1858-1917)

Sociologist and modernist

\begin{abstract}
Much of the discussion around blockchain-based smart contracts has focused on whether or not they operate in the same way as legal contracts. However, it is argued that most contracts are social rather than legal in nature and are entered into because the parties trust each other to perform the agreed exchange. Little has been written to address how the blockchain's trust protocol can enable the kind of social contracting that characterized the way exchanges were conducted before the Internet. This article aims to fill that gap by exploring blockchain-based smart contracts primarily as noncontractual social exchanges.
\end{abstract}

\section{Introduction}

Stewart Macaulay's seminal 1963 article "Non-Contractual Relations in Business" explored why merchants and manufacturers often fail to plan their commercial relationships and why they seldom resort to legal sanctions to settle disputes. Macaulay found that, in many business exchanges, detailed planning and legal sanctions play only a small role. His tentative explanation was that businesses prefer to deal with people or organizations they trust based on their prior dealings or their reputation. According to Macaulay, a manifestation of trust might be a brief conversation followed by a handshake. The rationale is that, if parties cannot rely on promises as being made in good faith, and plan for the future accordingly, the cost of uncertainty would make conducting business impossible. However, this approach to contracting frustrates lawyers, who advise their clients to plan for contingencies and formalize their business arrangements.

This article will apply Macaulay's behavioural analysis of business exchanges to smart contracts. In particular, it will examine the way that blockchain can provide and build trust and reputation while also managing the per- formance of the exchange. Once the management of performance of a smart contract is explained and understood, it is possible to give expression to the way that blockchain manages good faith in online business exchanges. In this way, blockchain solves a significant problem for anyone wanting to do business online.

\section{Situating Smart Contracts within Contract Theory}

Smart contracts enabled by blockchain technology are programmable applications that manage exchanges conducted online. Those exchanges would usually be an asset in exchange for value (but could be an asset in exchange for another asset, or one value for another value that is in a different currency). In the case of blockchain technology, value may be represented by a digital token, such as Bitcoin or another cryptocurrency. Much of the discussion around smart contracts enabled by blockchain technology has focused on whether or not they operate in the same way as legal contracts. However, legal contracts are not usually the focus of discussion when exchanges are conducted offline. This disconnect between the treatment of exchanges managed by smart contracts and exchanges in 


\section{Smart Contract Relations in e-Commerce: Legal Implications of Exchanges Conducted on the Blockchain Philippa Ryan}

the analogue world is probably due to a combination of factors including the word "contract" in the term "smart contract", and also the claim made by many blockchain developers and advocates that this innovative technology can provide and manage trust between the parties. There is a further important factor that considers the nature of contractual relationships: they are often founded on custom and conversation. According to Doddridge, legal principles are derived from logic, natural philosophy, cannon, and finally, from "the customs and conversations of men” (Doddridge, 1630).

In order to distinguish contracts established by custom and conversation from those that are founded on terms and conditions, it is useful to reflect on existing contractual theory. For example, Weber's (1922) distinction with an analysis of freedom of contract between what he described in the 1920s as the traditional "status contract" and the (then) modern "purposive contract". The former describes the complex social web of inter-relationships that arise when members of a community contract with each other to meet their economic and personal needs. The contracting members of this ecosystem change organically as they enter into agreements to accommodate the symbiotic relationship with the other members of the network. The latter (that is the "purposive contract") refers to legal claims made by one against another without necessarily being personally acquainted with each other. This discussion readily applies to the consideration of the use and legal implications of smart contracts because so much of the discourse around smart contracts has so far concentrated on their legality and how contracting parties will assert their rights and obligations. However, it is suggested here that their use is more social than legal and that the status of the parties to a smart contract prevails over their legal relationship. Indeed, when most people conduct business over the Internet, they are less interested in the legal consequences of those transactions than the interconnectedness that results from the exchange. This can be seen in the way that people rate their experiences on eBay, Uber, and TripAdvisor. Users of these service providers rate their experience with the vendor based on the quality and timeliness of the delivery of the service or product. These ratings create reputation for the service provider and build relationships of trust in the network or community. Even though the nature of the marketplace means that participants will very likely never meet, their interactions give rise to exchanges where the parties to the transaction are relying on each other's status established through these conversations, rather than their strict legal rights expressed in terms and conditions.
At the time that Weber was writing about economy and society in 1920s Germany, electricity was powering small-scale domestic appliances, including lights, sewing machines, telephones, recording equipment, and fans. As soon as a premises was connected to electricity, the business or householder could buy and use lights and appliances powered by electricity. To pay for this service, a contract arrangement would be entered into between the customer and the electricity company. Electricity companies employed and trained meter readers to attended to households and to note down exact consumption in order to generate a bill so that the owner or tenant of the premises could pay their usage, usually on a monthly basis. The meter reading, the calculation of consumption, the generation of the bill, and the payment were all conducted manually.

Clearly, smart contracts can manage financial interactions between machines, vehicles, humans, regulators, government, and financial service providers. Indeed, many of these processes are already managed online via processes that are automated. However, at this time, some steps along the path still require human intervention. For example, in order to pay for electricity, a service provider needs to calculate the amount owing by measuring consumption and then applying a formula that generates an invoice. These processes (the register of consumption, the calculation of the amount owing, the generation of the invoice, and its delivery via email) are all currently automated and (as long as there are no disputes) they require no human intervention. The only step along the way that requires a human to do something is when the customer pays the invoice.

If the human steps are to be replaced by automated processes, then it is important to ensure that this step emulates the appropriate human interaction. For example, if the payment of an electricity bill is currently done by authorizing a funds transfer from the customer's bank account to the electricity company's bank account and nothing more, then the automated processes should simply emulate this process. A smart contract could manage all of these steps without the need for any intervention. Any requirement to enter a password or in some other way to verify the customer's authorization of the payment can be readily bypassed by providing pre-authorization for all of these types of payments. The pre-authorization and direct funds transfer of payments to financial organizations and other service providers has been a part of the online banking ecosystem for more than two decades. Including this step in smart contracts is a next logical step in the way that online transactions will be managed. 


\section{Smart Contract Relations in e-Commerce: Legal Implications of Exchanges Conducted on the Blockchain Philippa Ryan}

It is important to note in this description of how we use and pay for electricity that a close reading of the terms and conditions of use of the electricity and the legal implications or obligations that arise from incurring a debt to the electricity company are not usually regarded as a necessary step in making such an arrangement. This is because the human experience of consuming and paying for utilities, products, and services such as water, gas, electricity, garbage collection, sanitation, food, petrol, and public transport is a custom with which most people are familiar.

In the day-to-day workings of developed economies, few disputes arise between consumers and those who deliver and sell these types of goods and services. Legal scholarship that focuses on the contract lawsuit, as opposed to contractual relationships, creates a distortion of most social norms and economic systems (Macaulay, 1977). Since the advent of the Internet, many of the payments and invoices for these transactions are managed online, but the nature of the exchanges remains a social experience. These types of contracts are very different in nature to the purchase of a business or an investment in property. These commercial arrangements require due diligence to be conducted on the target and perhaps legal advice in relation to the terms and conditions upon which the purchase or investment will be made.

Weber's (1922) understanding of different types of contracts is applicable to an analysis of how smart contracts will fit into our future of online exchanges and it favours the characterization of these relations as conversational and social, rather than strictly legal and purposive.

The question of whether or not a smart contract is also a legal contract is only necessary when considering its use. In most cases, the answer will be more intuitive than deliberate. This reflects the way that contracts are currently conducted both online and offline. It is usually unnecessary because smart contracts are a thoroughly modern extension of Weber's notion of a conversational or social relationship, and they are an example of the law "in action" as opposed to the law "on the books" (Leib \& Eigen, 2017).

The way that contracts are experienced is not so much about the law as it is about human interaction. Contract formation and enforcement are almost entirely about the law of the threat of legal enforcement in case a dispute arises. This is understood in the context of social contracts. The types of contracts that demand close attention to and legal expression of the terms and conditions are those that give rise to enduring relationships that require significant investment or those that expose one or both parties to high levels of risk. The need to reduce terms to a written contract rarely arises in relation to small, low-risk, ongoing transactions.

In the modern age of smart contracts, much of this human interaction is online. Archetypal contracts are contracts derived from an archetypal set of exchange conditions. These conditions include some bilateral, pre-consent negotiation, a general understanding by both parties that an enforceable obligation is being undertaken, a general understanding of the terms, a general understanding of the consequences of breach of those terms, and some direct or indirect relationship between the benefit of the bargain and the contract itself (Kastner, 2010). These foundational components of the collective imagination about "contract" sustain its sociological and normative legitimacy (Eigen, 2008). It is these descriptions of contract that are found in legal textbooks. However, modern online exchanges do not include the traditional behavioural characteristics of contract formation. Whereas traditional offline contracts were sealed with a handshake or a signature, modern online exchanges can be agreed to with a click (Eigen, 2008). Examples of this modern exchange would be the online purchase of digital music or the placement of a bid via online auction sites, which often requires pre-registration with a credit card and then the click of a button during the live auction. There are more sophisticated ways to shop online for physical items that emulate the offline retail shopping experience. For example, purchasing a product from a digital store involves selecting the item and its addition to a "shopping cart", the option to "continue shopping", and then the payment for all items in the cart at the virtual "checkout". Online shopping is not a radical departure from the way that the common law regards the shopping experience. The moment when the contract is entered into happens when the customer makes the offer to purchase at the checkout. As Somervell (1953) noted, when the customer reaches the checkout, they can remove items from the cart and then choose to authorize payment. This analysis applies to both online and instore (that is, offline) purchases. If an online purchase is one that is available to any shopper, then in most cases, there is no need for the vendor to refuse the customer's offer to purchase the items and make the payment. 


\section{Smart Contract Relations in e-Commerce: Legal Implications of Exchanges Conducted on the Blockchain Philippa Ryan}

This article applies Macaulay's work in the 1960s and 1970s to the modern experience of smart contracts and, by analogy, to the trust mechanisms provided and managed by blockchain technology. In doing so, it is argued that smart contracts enabled by the blockchain are the archetype of contract in action, as opposed to contractual doctrine. The legal implications for blockchain are that its online exchanges will align closely to Macaulay's notion of non-contractual or social relations. Discussion about the nature of online exchanges conducted via smart contracts is better suited to a behavioural analysis of business exchanges than a doctrinal analysis of the law of contract.

\section{Macaulay's Behavioural Analysis of Tradi- tional Business Exchanges}

According to Macaulay's behavioural analysis of traditional business exchanges (Macaulay, 1963), most contracts are examples of the law in action. The law in action refers to how people and businesses use contracts to manage their lives; how disputes in the performance of contracts arise and are settled; and how the resolution of disputes affects the parties to the disputes and influences future parties to contracts. The emphasis is on what happens on the ground, empirically, not on what theoretically should or probably would happen if certain assumptions were true (Macaulay \& Whitford, 2015). It is argued here that this approach to the discussion of contracts is readily applicable to the way that humans will use most blockchain-based smart contracts. Of course, there will always be exceptions. The law and human experience generally have always managed to articulate exceptions. However, most contracts are social exchanges and most are conducted with little dispute, and most disputes are resolved by the participants without recourse to the law or lawyers.

For any contract system to function well, trust is an essential element (Eigen, 2008). Beale and Dugdale (1975) described similar dynamics in the relationships between engineering firms in Bristol, England. Again, this was research conducted in the mid-1970s pre-Internet era and at least a decade before there was any notion that business exchanges could be conducted online. Beale and Dugdale noted that the manufacturing companies spent minimal timing in contract planning. They surmised that was likely due to the existing familiarity between the companies. Because the parties to the transactions trusted each other, they perceived a low level of risk in their business dealings. Under these circumstances, any extensive negotiations would lead to delay and expense that was disproportionate to the risk of dispute. It was also observed that manufacturers were also concerned that too much negotiation might sour an otherwise peaceful relationship and break down important bonds of trust (Scott, 1997).

Social contracting is usually managed by codes of behaviour that direct the parties as to how they should behave (Scott, 1997). This is in contradistinction to the law, which operates to tell the parties what they must not do and what they must do. The difference is a question of mode/strength of enforcement: social norms are enforced by ostracism; positive law is enforced by sanction as expressed by a court order at the end of a litigious process. Social norms in contracting are important because they may be industry-specific and even contrary to the exact letter of the law. The relationship between the parties and their relative bargaining power will usually dictate whether one of the parties (usually the weaker of the two) will seek legal advice prior to contracting. However, most of the exchanges that happen online between organizations and consumers or customers do not involve large transactions and therefore would not justify the expense of seeking legal advice. The question of how online contracts are formed and the social norms that keep the parties from involving their lawyers is more relevant in the discussion of companies and firms doing business online with other business or industry organizations.

\section{Behavioural Analysis of Business Exchanges as Applied to Smart Contracts}

Bitcoin (bitcoin.org) is an electronic payment system employing cryptographic proof, instead of trust, in order to ensure that reversal of a transaction, once entered into, is impossible. Bitcoin was the first application to utilize what has become known as blockchain technology. Blockchain uses peer-to-peer data and certain of Bitcoin's components in order to reduce the need for trusted third parties in mediating bilateral communications. Blockchain technology enables an electronic payment system based on cryptographic proof that hashes and timestamps transactions into an ongoing chain of hash-based proof of work, allowing any two willing parties to transact directly with each other without the need for a trusted third party (Nakamoto, 2009). Smart contracts on blockchain networks are the next logical progression for the Internet. The Internet and globalization disrupted in many ways Macaulay's notion of social contracting. Business conducted online, 


\section{Smart Contract Relations in e-Commerce: Legal Implications of Exchanges Conducted on the Blockchain Philippa Ryan}

in different parts of the world, and in different timeframes does not lend itself to brief conversations and handshakes. Establishing trust and reputation in online exchanges has been a challenge for e-commerce.

Blockchain technology can streamline online exchanges and reduce corruption, mistakes, fraud, and tax evasion. This is possible because blockchain technology is at its least the most reliable online tracking system yet developed. With a timestamp server, a chain of timestamps is created that publishes the hash of the transaction and proves the data must have existed at a particular time. The proof-of-work system involves scanning for value and ensuring that it cannot be changed (Nakamoto, 2009).

\section{Blockchain can provide and build trust and reputation} Bitcoin operates on a blockchain network that has been touted since its inception as being "trustless". In this context, "trustless" does not mean that the participants on the network cannot be trusted. Instead, it means that there is no need for a trusted third party. Without a trusted party, transactions must be publicly announced. This is achieved via a system that allows participants to agree on a single history of the order in which transactions were received. The payee needs proof that, at the time of each transaction, the majority of nodes agreed it was the first received (Nakamoto, 2009).

For exchanges conducted purely online, there is little risk that one of the parties will not fulfil their part of the deal. This is because both the payment and the delivery are executed by the smart contract. The blockchain manages the exchange of the two. This scenario saves time and costs. It means that the parties to a transaction take a much more active role in meeting their respective obligations. The exchanges feel almost cash-like in their immediacy and immutability. Because transactions cannot be reversed, the need for trust is eliminated (Nakamoto, 2009). With these mechanisms in play, the network can advertise to everyone that a transaction has been completed and the reputation of the participants in the completed exchange is enhanced automatically for all to observe.

However, online transactions become a bit more complicated when the exchange is payment for the delivery of a physical item, for example a widget. The delivery of a widget would be managed off-chain and would require human intervention to complete delivery. In this case, one solution is for the smart contract to provide an escrow service until such time that the widget has been successfully delivered. Of course, this may reduce the risk for the party paying for the widget (they will not authorize release of the funds on escrow to the sender until they receive the widget), but it leaves the sender exposed to two obvious risks. The first risk is that the party receiving the widget does not release the funds from escrow. However, this risk is quite low as the terms of the escrow will mean that the funds remain held in suspense until the dispute about delivery of the widget is resolved. The second risk to the sender is that the widget is sent to the wrong recipient, stolen, or not delivered for some other reason. In this case, the sender has parted with the item but has not been paid. This second risk can eventuate as readily off-line and offchain as it can on-chain. The blockchain does not give rise to the risk of the missing widget and it cannot eliminate it. Equally, the presence of a bank or trusted third party would not have reduced or eliminated that risk. In practical terms, where the transaction value is low, the party at risk is likely (implicitly) to assume (that is, accept) the risk. When the transaction value is high, the risk solution probably lies in an insurance policy.

As we can see, these qualities of blockchain technology as applied to commercial transactions are not absolute, but are dependent on the circumstances.

To appreciate the importance of proving and managing trust in e-commerce, it is important to consider the notion of uncertainty, perceived risk, and unreliability. The more certain the parties are that something will happen, the less they need to consider whether or not they trust it (Christopher, 2017). When business is conducted online, trust becomes even more important. The usual norms associated with personal contact and social interaction are not available. The parties cannot rely on their intuitive judgements about a person's trustworthiness. This is why credit card companies are enlisted for these transactions - the credit card provider has done the due diligence.

In order to eliminate credit card companies and other trusted (but expensive) third parties from the transaction network, the blockchain has mechanisms to build reputation for its participants.

Trust is built when the blockchain confirms to the entire network that a transaction was completed. Building reputation requires a broader dynamic. The ability to assess the reputation of a member in an online community is an essential need that arose with the launch of the Internet. The reputation gained by sellers and 


\section{Smart Contract Relations in e-Commerce: Legal Implications of Exchanges Conducted on the Blockchain Philippa Ryan}

buyers in e-commerce communities like eBay is based on the feedback they provide about each other after the conclusion of a commercial transaction. This reputation rating system is vital for all e-commerce because reputation creates trust, and without trust there can be no commerce (Rietjens, 2006, 55).

Many Bitcoin exchanges have designed trading platforms that provide information about the number of trades undertaken by each trader and the ratings provided by other users. The feedback is represented by colour-coded dots and percentage rankings to reflect each trader's level of recent trading activity and the satisfaction of their customers. However, these apps are not built into the blockchain network and so suffer from a lack of decentralization; they depend upon the trustworthiness of those providing the feedback.

It is an essential ingredient of any e-commerce reputation system to manage the integrity of feedback and to ensure that it is provided only by genuine users (and not, for example, by fake identities created by the person or persons who want to synthesize an improvement in their reputation). Anyone can browse eBay, but in order to join in the business of this community, buyers and sellers must first be registered with the platform. Exchanges are only possible when users are signed into the system with their unique identities. Users do not usually use their real name or identity on eBay. Instead, users have a pseudonym (for example, "carlover" or "allroundaussie"). Although these pseudonyms protect the privacy of the members of the community, they are linked back to genuine pre-validated email addresses and credit cards. This system ensures that real people are the puppet-masters of their avatars and that they must behave according the rules of the marketplace. Under the rating system, the more stars received by a member, the more reliable and trustworthy they are, increasing their popularity with other members, and thereby resulting in significant economic advantages for those users (Kollock, 1999).

In the case of reputation of goods and services and their suppliers, the solutions available to prevent feedback abuse are generally reliable but centralized under the control of a few large Internet companies. However, by building a decentralized and distributed feedback management system on top of the blockchain, it is possible to provide reliable reputation ratings (Carboni, 2015). A key feature of this system would be to attach more weight to the feedback of an established and trusted user on the network than new identities.
This is important for anyone wanting to conduct business with a particular person or organization for the first time. eBay manages this by allowing new sellers to offer only a small number of items for sale until they reach a certain level of trustworthiness, as established by the feedback ratings from those first-run customers. Reputation is preserved in this way as a reflection of how much the users of a network trust another participant.

\section{The Legal Implications for Blockchain and the Law in Action}

There are two approaches for parties to adopt when agreeing to manage their financial and asset exchanges via a smart contract. First, they can let all of the programmable logic and code in the smart contract represent the agreed terms and conditions. The problem with this approach is that it may be difficult for one of the parties to know how to read the code and therefore understand how it will behave. The second approach is for the parties to share an external document that discloses all the legal terms and conditions that will bind the parties and that may in part also reflect the way that the smart contract will behave. This too has its dangers. For example, it would be important to ensure that whatever is said in the external document accords with the way that the code will behave. Relying on the established doctrine of mistake, the parties would by mutual agreement or upon receipt of a court order modify the code of a smart contract to reflect their actual intention. This should be sufficient to ameliorate any concerns arising from the very real possibility of mistake.

If trust has already been established between the parties, there will be little cause for concern as to what the code will do or whether or not there is an external document that articulates in plain English (for example) the way that the code will behave. There are certain behaviours in the physical world that are undesirable and obstructive in business, but which are circumvented by smart contracts. For example, oppression, delay, or hold up. Hold up occurs when one contracting party threatens another with economic harm unless they grant a concession of some sort to the threatening party. When a smart contract is managing the exchange between the parties, the obligations on both sides of the transaction are effected simultaneously and subject to the agreed terms that have been coded into the application. The nature of smart contracts confines their use to certain types of online 


\section{Smart Contract Relations in e-Commerce: Legal Implications of Exchanges Conducted on the Blockchain Philippa Ryan}

transactions or transactions where payment will be automated upon the tracking of a certain event. This makes it difficult for one of the parties to cause delay in delivery or payment.

Because contracts are social tools as well as legal instruments, expectations and relationships are as important in contracting as legal obligations (Levy, 2017). In an online business environment, it may be easier to communicate to the rest of the community (for example via social media) if there is an untrustworthy participant, but the system is not immune to malicious attacks. Because reputation is built on feedback, the effect of this phenomenon makes it more problematic for business to suffer a bad review than to be sued for failing to meet a certain obligation under a contract. Any self-correcting mechanism could enhance the trust protocols that underpin the technology. This issue supports the case for a decentralized and possibly incentivized feedbackbased reputation system to be built into blockchain technology.

What is missing from this discussion are the obvious problems that may arise when a smart contract fails to deliver on its promise or does not behave in a way that was expected by the parties. The legal consequences of these circumstances give rise to their own peculiar problems. For example, identifying pseudonymous parties, deciding jurisdiction, and options for the nonlitigious resolution of the dispute. These problems vary in magnitude and volume depending upon the types of blockchain networks and environments that underpin the smart contracting. For example, the public Bitcoin blockchain is permissionless and operates as a financial transaction network. These smart contracts have very different features to those that may arise in private chains, where users are known to the system.

The problems arising where the users are known only by their pseudonyms and where jurisdiction is in dispute are more relevant to and prevalent in a public chain environment. However, these problems are not insuperable and nearly always arise in large public blockchain environments (such as Bitcoin). If the parties know each other and could have resolved these matters in an analogue transaction, there is no impediment to them resolving or prosecuting a dispute in the usual way.

\section{Conclusion}

In summary, this analysis has focused on the way that blockchain's trust and reputation protocols have restored to online business some of the features of social contracting that were lost with the advent of the Internet. Blockchain-enabled smart contracts bring more certainty and reliability to online transactions than has been available to e-commerce environments for the past twenty years.

It is clear that smart contracts will serve an important function in the automation of transactions as more of our business and social exchanges migrate to programmed applications and platforms that manage our online relationships. To ensure this smooth transition and to support the network of social contracts that sit within this ecosystem, it is important to keep in mind that not all transactions and exchanges are purposively contractual in a legal sense. Those who program and use smart contracts will benefit from delineating between social exchanges versus commercial contracts, as well as contracts that create enduring relationships from those that manage more casual affairs. Smart contracts can deliver significant benefits to the way that we manage supply chains and regulate variable payments. As research continues into the use of smart contracts, it will be useful to look at the way that different types of social exchanges are conducted in the analogue (offline) world, in order to emulate that experience online.

\section{About the Author}

Philippa (Pip) Ryan is a Barrister and Lecturer in the Faculty of Law at the University of Technology Sydney (UTS), Australia. Her PhD reclassified the liability of third parties to a breach of trust. Her current research explores contracts and trustless relationships enabled by blockchain technology. Pip designed and coordinates legal technology subjects and in conjunction with the UTS Connected Intelligence Centre, she is developing writing analysis software to improve students' self-assessments. She is on the industry advisory board of the Australian Digital Commerce Association, she is the Deputy Chair of the Australian Computer Society's Blockchain Technical Committee, and she is a member of the Standards Australia Blockchain Technical Committee. 


\section{Smart Contract Relations in e-Commerce: Legal Implications of Exchanges \\ Conducted on the Blockchain Philippa Ryan}

\section{References}

Beale, H., \& Dugdale, T. 1975. Contracts between Businessmen: Planning and the Use of Contractual Remedies. British Journal of Law \& Society, 2(1): 45-60.

http://doi.org/10.2307/1409784

Carboni, D. 2015. Feedback Based Reputation on Top of the Bitcoin Blockchain. ArXiv.org.

https://arxiv.org/abs/1502.01504v2

Christopher, C. M. 2016. The Bridging Model: Exploring the Roles of Trust and Enforcement in Banking, Bitcoin, and the Blockchain. Nevada Law Journal, 17(1): 139-180.

Doddridge, J. 1630. The English Lawyer. London.

Eigen, Z. J. 2008. The Devil in the Details: The Interrelationship Among Citizenship, Rule of Law and Form-Adhesive Contracts. Connecticut Law Review, 41(2): 389-430.

Kastner, T. 2010. The Persisting Ideal of Agreement in an Age of Boilerplate. Law \& Social Inquiry, 35: 793-823. http://dx.doi.org/10.1111/j.1747-4469.2010.01202.x

Leib, E. J., \& Eigen, Z. J. 2017. Consumer Form Contracting in the Age of Mechanical Reproduction: The Unread and the Undead. Illinois Law Review, 2017(1): 65-109.

Levy, K. E. C. 2017. Book-Smart, Not Street-Smart: Blockchain-Based Smart Contracts and The Social Workings of Law. Engaging Science Technology and Society, 3: 1-15.

https://doi.org/10.17351/ests2017.107

Kollock, P. 1999. The Production of Trust in Online Markets. In E. J. Lawler, M. Macy, S. Thyne, \& H. A. Walker (Eds.), Advances in Group Processes: 99-123. Greenwich, CT: JAI Press.

Macaulay, S. 1963. Non-Contractual Relations in Business: A Preliminary Study. American Sociological Review, 28(1): 55-67. http://dx.doi.org/10.2307/2090458

Macaulay, S. 1977. Elegant Models, Empirical Pictures, and the Complexities of Contract. Law \& Society Review, 11(3): 507-528. http://doi.org/10.2307/3053130

Macaulay, S. \& Whitford, W. C. 2015. The Development of Contracts: The Law in Action. Temple Law Review, 87: 793-806.

Nakamoto, S. 2009. Bitcoin: A Peer-to-Peer Electronic Cash System. Bitcoin.org. https://bitcoin.org/bitcoin.pdf

Rietjens, B. 20016. Trust and Reputation on eBay: Towards a Legal Framework for Feedback Intermediaries. Information \& Communications Technology Law, 15(1): 55-78. http://dx.doi.org/10.1080/13600830600557935

Scott, J. 2009. Empirical Studies Strike Back against the Force of Contract Theory. UCL Jurisprudence Review, 4: 256-257.

Somervell, L. J. 1953. Pharmaceutical Society of Great Britain and Boots. [1953] 1 QB 401; [1953] EWCA Civ 6; [1953] 1 All ER 482, [1953] 2 WLR 427.

Weber, M. 1968. Economy and Society. G. Roth \& C. Wittich (Eds). Oakland, CA: University of California Press.
Citation: Ryan, P. 2017. Smart Contract Relations in eCommerce: Legal Implications of Exchanges Conducted on the Blockchain. Technology Innovation Management Review, 7(10): 14-21.

http://doi.org/10.22215/timreview/1110

Keywords: blockchain, legal, law, smart contracts, trust, reputation, online transactions (cc) BY 


\section{Academic Affiliations and Funding Acknowledgements}
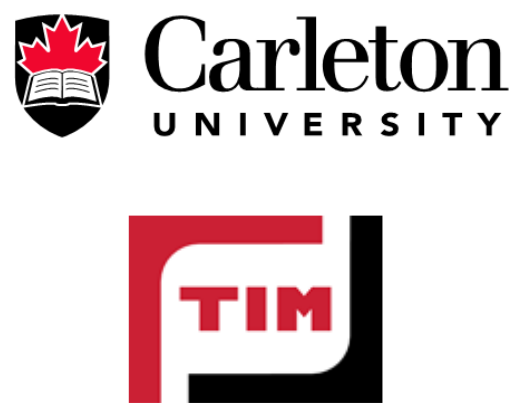

Canadà
Technology Innovation Management (TIM; timprogram.ca) is an international master's level program at Carleton University in Ottawa, Canada. It leads to a Master of Applied Science (M.A.Sc.) degree, a Master of Engineering (M.Eng.) degree, or a Master of Entrepreneurship (M.Ent.) degree. The objective of this program is to train aspiring entrepreneurs on creating wealth at the early stages of company or opportunity lifecycles.

- The TIM Review is published in association with and receives partial funding from the TIM program.

The Federal Economic Development Agency for Southern Ontario (FedDev Ontario; feddevontario.gc.ca) is part of the Innovation, Science and Economic Development portfolio and one of six regional development agencies, each of which helps to address key economic challenges by providing regionallytailored programs, services, knowledge and expertise.

- The TIM Review receives partial funding from FedDev Ontario's Investing in Regional Diversification initiative. 